\title{
Research on Logistics Service Platform of Small and Medium Sized Electronic Commerce Enterprises Based on Internet of Things
}

\author{
Hui-zhen WANG \\ Xi'an International University, Xi'an Shaanxi in China, 710077
}

Keywords: Internet of things, Small and medium-sized e-commerce enterprise, logistics service platform.

\begin{abstract}
Logistics has become a bottleneck for the rapid development of e-commerce enterprises, especially for small and medium enterprises, which can not self built logistics facilities and logistics business, this part of the enterprise can only outsource logistics business, logistics efficiency is an important factor affecting the rapid development of e-commerce enterprises, the lack of an effective connection platform of small and medium enterprises and small and medium sized logistics enterprises affects logistics efficiency. At the same time, the Internet of things in the logistics industry has a certain application, which will promote the rapid development of the logistics industry, so this paper is aimed at small and medium electronic business enterprise to build a logistics service platform based on the Internet of things, in order to promote the rapid development of small and medium e-commerce enterprises to provide some reference.
\end{abstract}

\section{Introduction}

In recent years, With the development of Internet technology, E-commerce has been rapid development, the November 11, 2015 day Taobao sales reached 90 billion yuan, in the face of such a large amount of sales logistics can not guarantee the quality and quantity of goods delivered to the hands of customers, and some even have to wait for half a month, so the logistics has become the bottleneck of rapid development of electronic commerce. Like Jingdong, Dangdang is relatively large e-commerce enterprises, which can self built logistics system to provide the required logistics services, but most of the electronic commerce enterprise in Taobao have not the ability, so it is urgent to develop a rapid development of modern logistics. In recent years, the combination of the Internet of things and logistics has been put into the logistics. Based on this, this paper tries to establish a logistics service platform based on the Internet of things, and hope to provide some reference for the collaborative development of small and medium-sized e-commerce enterprises and logistics enterprises.

\section{The Internet of Things}

The Internet of Things is an important part of the new generation of information technology. It is the Internet of things. The concept of the Internet of things has two meanings: first, the core and the basis of the Internet of things is the Internet, which is based on the Internet. Second, the user end extends and extends to any goods and goods, information exchange and communication. The key technologies of the Internet of things are sensor technology, radio frequency identification (RFID) technology, global positioning system (GPS) technology, infrared sensors, etc.. The object of the Internet of things is to realize the connection between the object and the 
object, the object and the person, all the goods and the network, in order to facilitate the identification, management and control.

\section{The Impact of the Internet of Things on All Aspects of Logistics}

The logistics industry is an industry which has introduced the Internet of things early. The marriage of the Internet of things and logistics, will give a relatively large impact on all aspects of the traditional logistics. The following is a discussion of the impact of the Internet of things on the main aspects of logistics:

Transport Links. There are a lot of factors involved in transport links: drivers, goods, transport vehicles, transport routes, etc.. For example, the driver, who plays a key role in the success of transportation, in the transport link is very important, but in the traditional logistics conditions it is also difficult to manage the driver. So-called to has not affected by external military orders, without the introduction of networking and other information technology, it is impossible for logistics company know where is the drivers, which can only be used in extensive management. For example, there are a number of customers urgent need of the goods, the goods need to be sent to the client side, but the driver for the province's high-speed toll roads and take ordinary road, the last is likely not to reach the customer, but if the traditional logistics management, management of the driver of this line is difficult to monitor in place. The same transport vehicles, transport routes, etc. also exist such a situation. There are also, such as some drugs in accordance with the provisions of the transport process must be refrigerated. Cold chain of transport of a cold chain (manufacturers to distributors) of the temperature should be maintained at minus $20^{\circ} \mathrm{C}$, the two frozen chain (distributors to the wholesale and retail stores) require temperature to remain below $18^{\mathrm{O}} \mathrm{C}$, the three level of cold chain (wholesale station to terminal outlets) the temperature to remain below $15^{\mathrm{O}} \mathrm{C}$. Does the temperature at which these are achieved in the course of transportation? Is there a standard for the transport of precision instruments to meet customer requirements? If you do not do so will cause a lot of unnecessary losses, some security issues will also be very likely to appear. But these problems once introduced technology of the Internet of things will be easily solved, through, for example, on the vehicle installed GPS positioning device can real-time understanding of the drivers of the specific location, then driver to collect along the route information. A variety of sensors and tags are installed on the goods to collect the information of the goods in transit, and to return the data to the data center. Management department can always grasp the location information of the vehicle, the temperature information of the goods, the transport conditions in the vehicle, the vehicle's oil pressure information, and so on, but also can support real-time video. Such in the data management center of the transport vehicles can be in accordance with the reasonable path to complete the transport link, in addition, the driver can also pass the sensor to understand whether they are speeding, goods are abnormal, etc.. With the accession of the Internet of things, said before a series of problems can be solved, the efficacy and safety of transport links and guaranteed.

Storage Link. In addition to transport, A very important link in Logistics. Some companies have their own warehouses to store goods, but also a number of companies rent the logistics company's warehouse, whether it is their own warehouse or rented warehouse, Companies are very concerned about whether the storage conditions can meet the needs of the company's goods. In particular, some goods have special requirements, such as tea on the temperature and air cleanliness requirements, fresh food and cold drink on the temperature have strict requirements, the storage of the 
environment temperature and humidity are required, in the traditional storage conditions, It is difficult to know whether the storage conditions are not standard, but in the era of Internet of things, Only a number of sensing chip in the warehouse, you can sense the information you want to know. The goods with Electronic label, intelligent reader device will automatically read out the label information of the storage and goods. At the same time, the information is transmitted to the data management center; When goods are stored in the warehouse, the use of sensor and electronic chip can transmit the characteristics of the goods such as the production date, temperature, and the storage environment, such as air temperature, humidity and other data information to data management center, So as to realize the intelligent management of the data management center, also can provide the information service which they need to store the goods in the warehouse.

Loading and Unloading Process. In traditional loading and unloading, the quantity and variety of goods must be counted, and the efficiency is low. But in the era of Internet of things, It can realize automation of handling and inventory, such as during loading or unloading vehicle, automatic reading device through the real-time record the information and the information promptly transmitted to the data management center, management can real-time understanding of the goods location in order to achieve a better management. It can also provide customers with the specific location of the goods and goods, and the time to arrive at the information service.

Packaging and Distribution Processes. Different goods to the packaging and distribution processing have different requirements, such as explosive, flammable products, if not according to the standard operation, It is bound to bring great security accident; another example is the frozen food to the storage temperature requirements more stringent, Not in accordance with the provisions of the disposal, it will cause damage to property. But the reasonable use of the Internet of things can effectively avoid accidents and property losses, For example, in the event of packaging and distribution of flammable and explosive goods, the assembly workers can get real-time operation should be paid attention to in order to avoid the safety accidents caused by the negligence of the assembly workers.

Information Link. Logistics process will produce a large amount of information, and the traditional logistics background, these information is not collected, so the logistics process to become "black continent", the logistics process is opaque, it is difficult to find the unreasonable logistics, which is difficult to find the most appropriate way to control the high cost of logistics. However, the application of the Internet of things, data management center for the collection of logistics process data to make the logistics process more transparent, each member of the supply chain can get real information through data management center analysis, the authenticity of the information to help production enterprises to develop detailed production plan, and then help dealers adjust the purchase plan. Things information service is also very useful for consumers, consumers through the Internet of things technology can be traced through the logistics process and production process, thereby enhancing consumer confidence.

Distribution Link. Distribution link through the Internet of things technology can achieve the integration of orders to achieve more reasonable distribution, such as double 11 that day a person in a number of sites to buy a variety of goods, goods to the time is almost, if a day to sign for 4 times, just go upstairs and downstairs, very convenient, but the introduction of Internet technology can be integrated with the recipient's distribution, the same address and recipient can be sent, for courier companies and recipients are favorable. Through the Internet of things technology can 
real-time will related node information collection to the data management center, so as a result of the introduction of the Internet of things, let picking and delivery process more transparent, the customer through the query can arrange their own delivery time.

\section{Service Platform Based on the Inte rnet of Small and Medium E-comme rce Logistics}

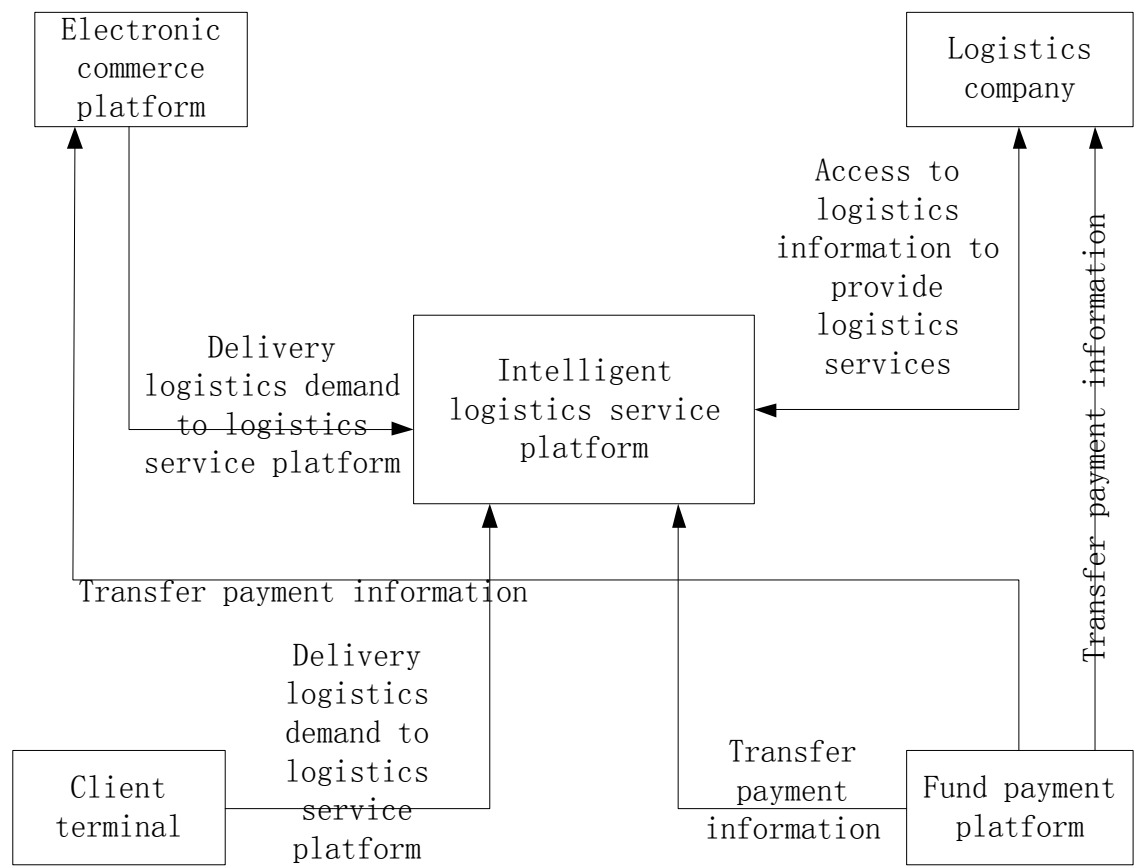

Figure 1. The logistics service platform for small and med iu m-sized electronic commerce enterprises based on Internet of things

Figure 1 is based on the electronic commerce enterprise logistics service platform, the logistics service platform is based on the two-dimensional code, RFID, GIS and other Internet technology to achieve the communication and interaction between people and people, people and objects, and to achieve more efficient management and resource allocation,.

Intelligent logistics service platform based on the Internet of things is the core node, through the connection of small and medium e-commerce platform, logistics companies, online payment platform and the client to allow small and medium electronic business enterprise to get the logistics service provided by the logistics company in time.

Service process: intelligent logistics service platform through e-commerce platform and obtain information flow and logistics to demand for small and medium-sized logistics companies, only a computer can through the intelligent logistics service platform for logistics industry needs to provide logistics services, and can complete the order contracts, orders and other operations through the platform, intelligent logistics service the platform for unified management of goods, delivery and other aspects; secondly, through the intelligent logistics service platform and logistics company's management information system to realize to the management of the logistics process; intelligent logistics service platform to optimize the configuration according to the data provided by the order information; finally, intelligent logistics service platform can be for services and capital platform the company provides a variety of docking pay settlement funds.

In a word, the positioning of the intelligent logistics service platform is integrating 
the flow of Commerce, logistics, capital flow, information flow and data flow is used to meet the needs of small and medium-sized e-commerce enterprises diversification. The rapid development of electronic commerce for intelligent logistics service platform to provide vast amounts of information on logistics demand, logistics services through intelligent platform for a large number of Waybill Information Demand of secondary integration to achieve a more reasonable distribution can be the for the development of electronic commerce industry has important significance.

\section{Reference}

[1] Lin Ling. Application and construction of the Internet of things technology in the logistics industry [D], Beijing University of Posts and Telecommunications,.2011.5.

[2] Jiang Yajun. Overview of the research on the Internet of things based on [J] Guangdong communication technology EPC, Guangdong communications technology.2005.

[3] Ning Huansheng, Zhang Yu et al. Research on the information service system of the Internet of things in China [J], electronic journal.2006.12.

[4] Wang Binghui, Ning Huansheng. RFID major project and the national Internet of things [M]. Machinery Ind ustry Press.2008.

[5] Mei Fangquan. The wisdom of the earth and perception of China - the development of the Internet of things [J], agricultural network information.2009.12.

[6] Yang Xia, He Gang, Liu Chuande, Wang Jing. Public information platform construction of $[\mathrm{J}]$ network, cooperative economy and technology.2012.7. 